\title{
Quality assurance of exhaust emissions test data
}

\author{
G Konstantas and A Stamatelos* \\ Mechanical and Industrial Engineering Department, University of Thessaly, Volos, Greece
}

\begin{abstract}
Tight requirements posed by the increasingly stringent legislation complicate the design procedure for exhaust aftertreatment devices and systems. Since design optimization relies heavily on experiments and tests, emissions test data acquisition should comply with strict quality standards. Time-varying exhaust emission measurements incorporate a wealth of information stemming from the engine type, its fuel injection and ignition management and valve timing and the exhaust gas treatment devices present. The objective of this paper is to present the preliminary development process of a test data quality assurance methodology that may be coded in the form of computer software. This paper is a first attempt in this direction and is based on 15 years of experimental and computational experience of the authors' laboratory in exhaust gas treatment testing and modelling. The methodology comprises three steps. The first step involves modal analysis of the driving cycles. This allows comparison between different types of engine and test procedure regarding engine management philosophy and exhaust aftertreatment characteristics. The second step involves a systematic data synchronization and preprocessing procedure, which significantly improves data quality. The third and most important part of the methodology involves systematic checking by means of molecular and elemental balance calculations.
\end{abstract}

Keywords: exhaust gas emissions, emissions testing, quality assurance, test data

\section{NOTATION}

$\mathrm{A} / \mathrm{F}$

A

$\mathrm{CO}$

CVS

EUDC

EURO 4, EURO 5

FID

FTP

F

$\mathrm{HC}$

LTTE

NEDC

$\mathrm{NO}_{x}$

MFR

PKE air-fuel ratio $(\mathrm{kg} / \mathrm{kg})$

air flowrate $(\mathrm{kg} / \mathrm{s})$

molar fraction of carbon

monoxide in the exhaust gas

constant volume sampling

extra-urban driving cycle

European emission standards

flame ionization detector

federal test protocol

fuel flowrate $(\mathrm{kg} / \mathrm{s})$

molar fraction of unburned

hydrocarbons in the exhaust gas

Laboratory of Thermodynamics

and Thermal Engines

new European driving cycle

molar fraction of oxides of

nitrogen in the exhaust gas

exhaust gas mass flowrate

$(\mathrm{kg} / \mathrm{s})$

positive kinetic energy

The MS was received on 22 April 2003 and was accepted after revision for publication on 19 February 2004.

* Corresponding author: Mechanical and Industrial Engineering

Department, University of Thessaly, 38334 Volos, Greece.

SI

$t$

$\Delta t$

$T$

UDC

UEGO

V

$V_{i}$

\section{Subscripts}

$i$

inlet

$n$

outlet spark ignition

time (s)

time duration of the microtrip

component (s)

exhaust gas temperature $\left({ }^{\circ} \mathrm{C}\right)$

urban driving cycle

universal exhaust gas oxygen

sensor

average vehicle speed $(\mathrm{m} / \mathrm{s})$

vehicle speed $(\mathrm{m} / \mathrm{s})$

discrete time period of duration $\Delta t$, component of the microtrip catalytic converter inlet number of discrete time components of the microtrip catalytic converter outlet

\section{INTRODUCTION}

Recent developments in exhaust aftertreatment devices have been driven by the need for cleaner transportation and the increasingly stringent legislation standards. Compliance with the ultralow emissions levels of EURO 4 
and EURO 5, and the respective US standards, pushes the catalytic technology to its limits. Systems of increasing complexity are introduced, which rely on the combination of individual aftertreatment components controlled by advanced engine management, which is assisted by the use of an increasing number of advanced sensors [1-3].

From the exhaust viewpoint, the overall powertrain comprises three main sections:

(a) the engine itself,

(b) the exhaust treatment devices,

(c) the integrated management system (sensors and ECU).

The above-mentioned sections are bound together by the flow of information contained in the exhaust gas, which can be coded mainly in terms of mass flowrate, temperature and species composition.

Obviously, the design and optimization of exhaust systems must be based on the processing of large quantities of transient exhaust gas data of the above type. For example, Fig. 1 presents a typical exhaust system measurement layout for the assessment of a common gasoline engine three-way catalytic converter system. The experimental facility usually comprises the following types of measurement device:

(a) thermocouples for the measurement of catalytic converter upstream, downstream and inside temperatures,

(b) accurate flow sensors (i.e. hot wires, hot films, etc.) for the reliable measurement of inlet mass flowrate,

(c) infrared exhaust gas analysers for $\mathrm{CO}$ and $\mathrm{CO}_{2}$,

(d) FID exhaust analysers for HC, (e) paramagnetic exhaust gas analysers for $\mathrm{O}_{2}$,

(f) chemiluminescence exhaust gas analysers for $\mathrm{NO}_{x}$,

(g) accurate electrochemical lambda (or even $\mathrm{NO}_{x}$, $\mathrm{CO}$, etc.) sensors.

If account is taken of the fact that the transient character, especially of the exhaust gas concentration, which fluctuates between lean and rich in a stoichiometric SI engine, usually necessitates faster than $1 \mathrm{~Hz}$ acquisition of the above data, it is not surprising that there exists a large variation in the attainable quality of acquisition of test data of this type between different test laboratories $[\mathbf{4}, \mathbf{5}]$.

Shifting to exhaust treatment systems, which result in ultralow emitting vehicles, means that in some cases the emissions are so low that emitted exhaust gas is cleaner than the ambient air. The ultralow emission concentrations generate losses in accuracy of data because of the limitations of both instrumentation measurability and the experimental set-up itself. Various laboratories are already investigating alternative layouts for more accurate measurements or developing very precise analytical instruments [6]. Another low-cost direction is the implementation of methodologies to control the quality of measurement data employed in design optimization of exhaust systems.

The adoption of quality assurance procedures, such as statistical quality control and total quality management of the experimental data, supports the optimized engineering design of the above complex exhaust treatment systems and hints at further improvement in measurement layouts and components. A test data quality assurance

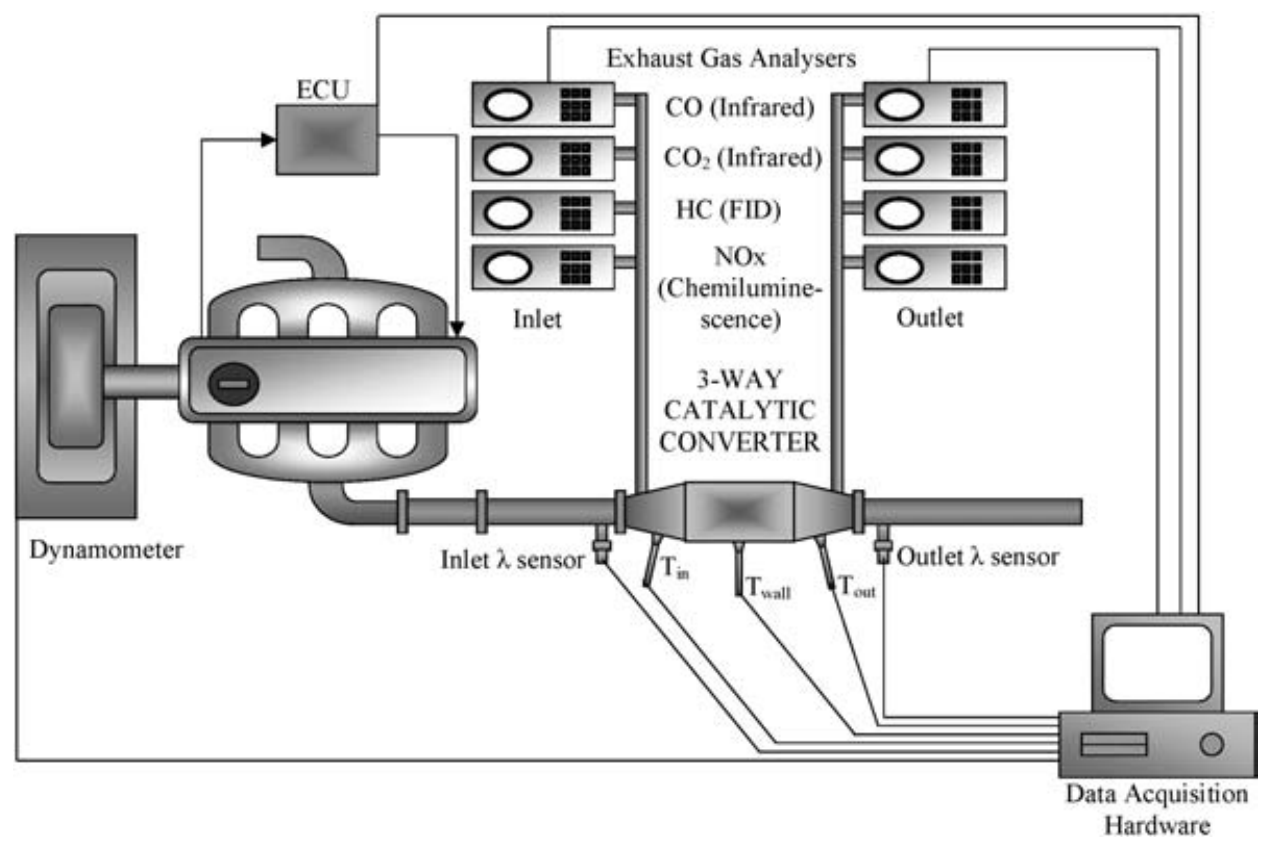

Fig. 1 A typical experimental setup of SI engine exhaust emissions tests. Exhaust gas is directly sampled from the exhaust line ( $\mathrm{HC}$ through the heated line). Several thermocouples measure the temperature upstream and downstream of and inside the catalyst, and a number of sensors are used for auxiliary measurements. Data are acquired through computerized acquisition systems 
procedure must be able to process the acquired test data, point to acquisition problems or experimental errors, accept or reject an experimental data acquisition file and extract further information concerning the overall operation of the system.

A preliminary quality assurance procedure comprising a number of simple steps is formulated in this paper. The procedure consists of three steps, as listed below:

(a) analysis of driving cycle modes,

(b) data synchronization and preprocessing,

(c) mass balance calculations.

These three steps comprise a number of qualitative (graphical methods and flow charts) and quantitative (statistical analysis, cross-checking calculations, database entries) processes.

The nature of the exhaust emissions test procedures and equipment usually generates several types of error and common problems in experimental datasets that can be summarized as follows:

(a) unphased data (different measurement piping length and response time of the analysers, as well as delays in the measurement chain, affect the correct phasing of the emission concentrations);

(b) inconsistent measurement scales and response between analysers (rapidly changing emission concentrations from high to low levels and vice versa, oscillations of analyser measurements);

(c) condensation of gas phases in the measurement lines;

(d) noisy lambda signal or bad sensing system calibration.
In the following sections, each one of the three steps of the proposed methodology is separately discussed.

\section{MODAL ANALYSIS OF THE DRIVING CYCLES}

Typical legislated driving cycles for the United States and Europe are presented in Figs 2 and 3 respectively. A driving cycle can be seen as a succession of the following different modes:

(a) acceleration mode,

(b) deceleration mode,

(c) cruising mode,

(d) idle mode,

(e) cold start [period when aftertreatment devices are inactive $\left.\left(T_{\text {exhaust }}<T_{\text {light-off }}\right)\right]$.

The engine and exhaust treatment devices operate differently in each one of the above modes, according to the specific engine management system and strategies applied by the engine manufacturer. Mixture enrichment is common during accelerations, while decelerations are characterized by fuel cut. During steady state operation (idle and cruise) the A/F ratio can be slightly rich, lean or close to stoichiometry, depending on the manufacturer settings $[\mathbf{2}, \mathbf{3}, \mathbf{7}]$. The initial period needed for the exhaust treatment devices to reach their light-off temperature is essential, because it produces about 50-80 per cent of the total cumulative tailpipe emissions of the legislated cycle.

A quantitative measure that can be employed to discriminate between the above-mentioned modes in a driving cycle has already been proposed by other

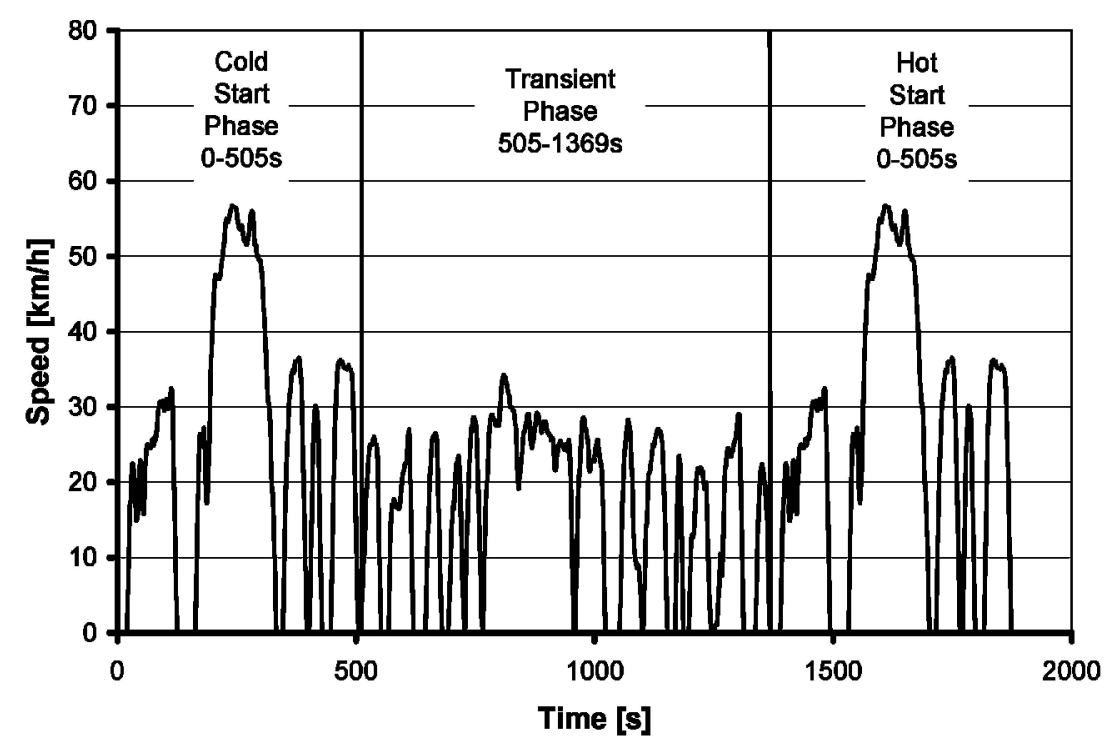

Fig. 2 Vehicle speed versus time during the FTP-75-legislated driving cycle. After the end of the transient phase, the engine is shut off for $10 \mathrm{~min}$, and the hot start phase begins afterwards 


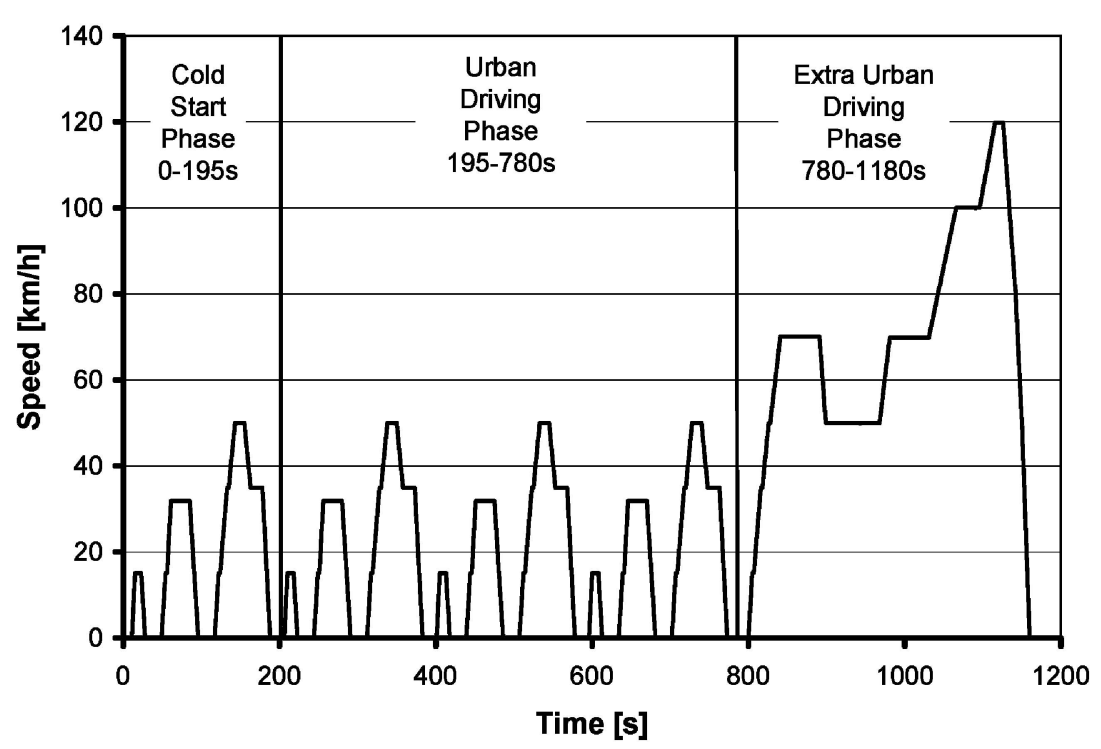

Fig. 3 Vehicle speed versus time in the NEDC-legislated driving cycle

researchers. It has been named the 'positive acceleration kinetic energy per unit distance' (PKE) [8]. It is defined as follows

$$
\mathrm{PKE}=\frac{\sum_{i=1}^{n}\left(V_{i+1}^{2}-V_{i}^{2}\right)}{\left(\sum_{i=1}^{n} V_{i} / n\right) \Delta t}=\frac{\sum_{i=1}^{n}\left(V_{i+1}^{2}-V_{i}^{2}\right)}{\bar{V} \Delta t}
$$

where $V_{i+1}$ is the final speed and $V_{i}$ is the initial speed in a positive acceleration $(a>0)$ manoeuvre that forms part of a trip or microtrip, and $\bar{V}$ denotes the average vehicle speed over the microtrip component of duration $\Delta t$. PKE has the units of acceleration and can be regarded as the representative acceleration for a microtrip (a stopto-next-stop driving segment), or for the complete trip.
In this work, PKE is extended and used as a definition of the instantaneous driving condition. In this extended definition, each microtrip is considered to be the distance travelled by the vehicle during a short time period, typically shorter than $1 \mathrm{~s}$, consisting of three time segments $(i=1,2,3)$. This distance is calculated as the average speed over the three time segments ( $n=3$ typically selected for smoothing), multiplied by this time period. Using the experimental vehicle speed and PKE, the driving cycle can be distinguished into acceleration, deceleration, cruise and idle modes. The experimental data are linked to each mode for further treatment, allowing in this way a better view of the engine and catalyst operation. Figure 4 shows the PKE and vehicle speed versus time.

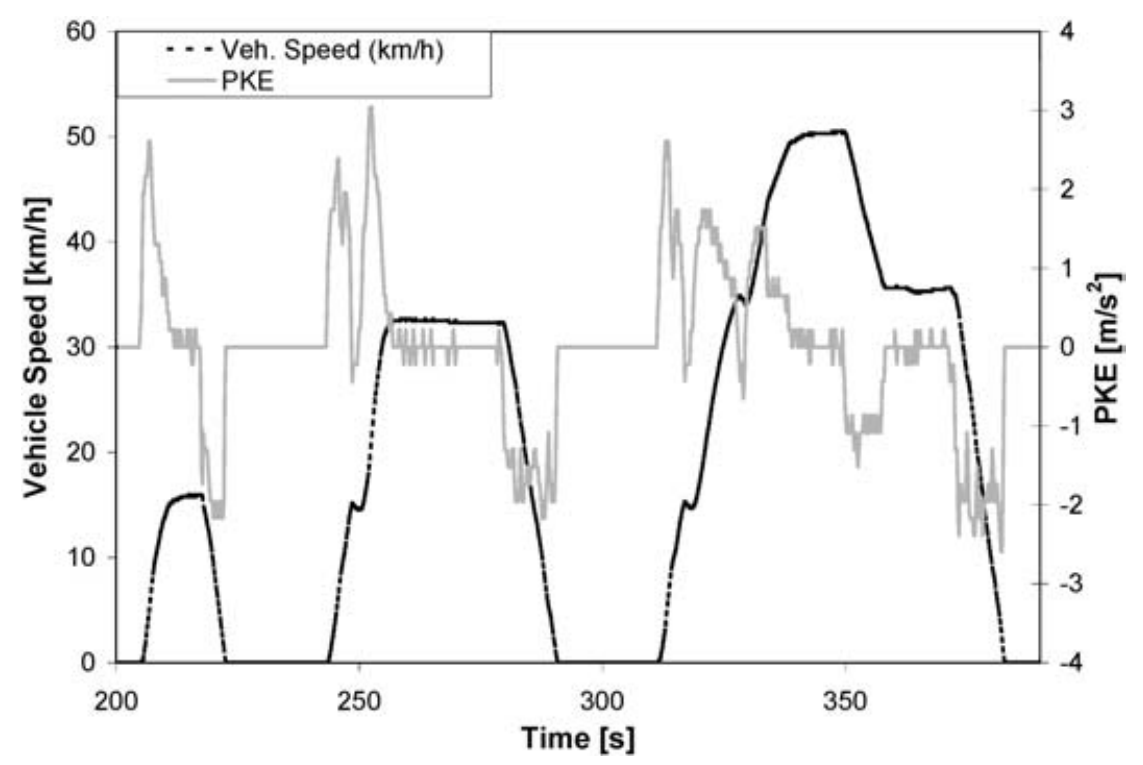

Fig. 4 Positive kinetic energy criterion and vehicle speed versus time during a part of the NEDC. In this way, the driving cycle is discretized into four modes: idle, cruise, acceleration and deceleration, depending on the values of PKE 
The assumption made is that for PKE $>0.2 \mathrm{~m} / \mathrm{s}^{2}$ the vehicle accelerates and for $\mathrm{PKE}<-0.2 \mathrm{~m} / \mathrm{s}^{2}$ the vehicle decelerates. The graph shows the distinction of each mode in the driving cycle, and it can be used as a criterion for the quality of the experiment. This is obvious in the gear changes during acceleration where PKE fluctuates.

An advantage of the implementation of PKE is that it allows the comparison between different driving cycles. An example is presented in Figs 5 and 6, where a 2.01 displacement, four-cylinder engine tested in the NEDC and a $4.61 \mathrm{~V} 8$ engine tested in the FTP-75 cycle are compared by means of their respective modal analysis data (see Table 1). These figures are produced by processing of engine-out, cumulative $\mathrm{CO}, \mathrm{HC}, \mathrm{NO}_{x}$ and $\mathrm{O}_{2}$ (molar) emissions during the individual modes of the driving cycle. Figure 6 presents only the one side of the two-bank exhaust system of the 4.61 engine. If overall emissions produced in the above two comparative cases are compared, it can be seen that the acceleration mode produces the highest emissions in both cases. This can be mainly attributed to the increased mass flowrate and mixture enrichment during acceleration. On the other hand

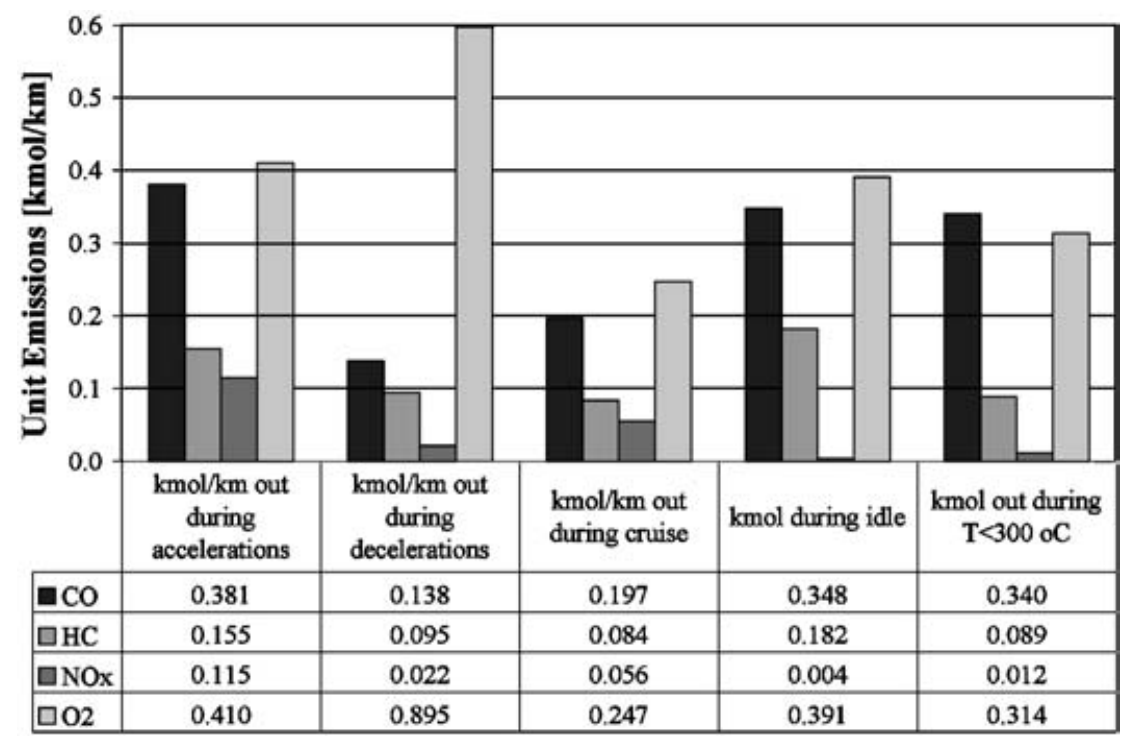

Fig. 5 Cumulative emissions per kilometre of a 2.01 engine during the NEDC. The engine management is tuned for slightly rich operation, a rich cold start and fuel cut during decelerations that assist oxygen storage filling. Increased $\mathrm{NO}_{x}$ emissions result from a relatively high compression ratio

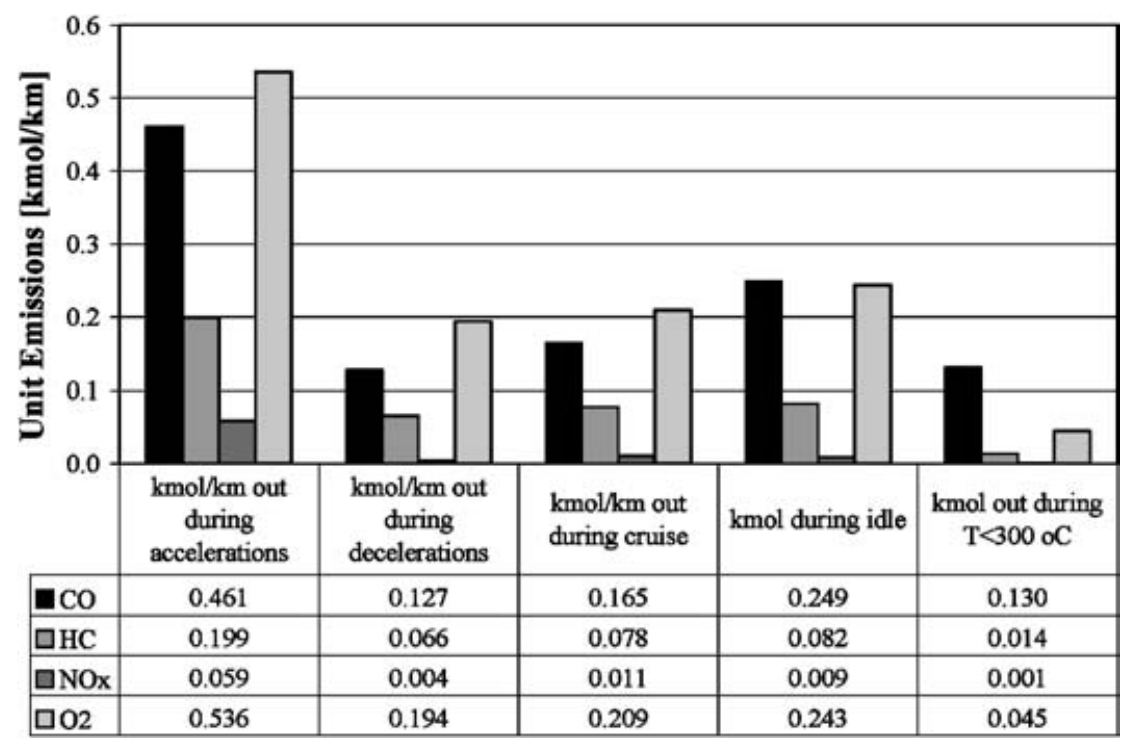

Fig. 6 Cumulative emissions per kilometre of a 4.61 engine during FTP-75. The engine is operating always close to stoichiometry, except during cold start where it shifts to a rich regime. This type of engine needs a catalytic converter focused mainly on oxidation processes 
Table 1 Main characteristics of the engines examined in this study

\begin{tabular}{llll}
\hline & Engine 1 & Engine 2 & Engine 3 \\
\hline Displacement $\left(\mathrm{dm}^{3}\right)$ & 2.0 & 4.6 & 1.0 \\
Cylinder arrangement & 4 in-line & V8 & 4 in-line \\
Compression ratio & 10.5 & 9.4 & 10.0 \\
Horsepower $(\mathrm{HP})$ & $138 / 6000 \mathrm{r} / \mathrm{min}$ & $224 / 4800 \mathrm{r} / \mathrm{min}$ & $50 / 5000$ \\
Lambda operation & Slightly rich & Stoichiometric & Slightly lean \\
\hline
\end{tabular}

the 21 engine produces higher overall $\mathrm{NO}_{x}$ emissions because of its higher compression ratio. Also, this engine appears to have an overall excess of $\mathrm{O}_{2}$, but this is obviously due to the fuel cuts during decelerations, while the 4.61 management seems to be tuned for close to stoichiometry operation in each mode. Finally, the 4.61 engine achieves faster light-off, resulting in reduced cumulative emissions. Table 2 presents the average lambda values and their respective standard deviations for each mode. The lambda values are obtained by means of UEGO sensors in both cases. In general, the control of the 4.61 engine is very 'tight' and close to stoichiometry, in contrast to that of the 2.01 engine. This is reflected

Table 2 Mean lambda values and respective standard deviation in the different states of the driving cycles

\begin{tabular}{llllll}
\hline & \multicolumn{2}{c}{2.01} & & \multicolumn{2}{c}{4.61} \\
\cline { 2 - 3 } \cline { 5 - 6 } & Lambda & $\begin{array}{l}\text { Standard } \\
\text { deviation }\end{array}$ & & Lambda & $\begin{array}{l}\text { Standard } \\
\text { deviation }\end{array}$ \\
\hline Acceleration & 0.990 & 0.032 & & 1.001 & 0.017 \\
Deceleration & 1.872 & 1.165 & & 1.010 & 0.029 \\
Cruise & 1.006 & 0.160 & & 1.002 & 0.016 \\
Idle & 0.996 & 0.122 & & 0.998 & 0.037 \\
$T<300{ }^{\circ} \mathrm{C}$ & 0.984 & 0.275 & & 0.941 & 0.066 \\
\hline
\end{tabular}

in the standard deviation of the lambda signal of the 4.61 engine, if it is compared with the standard deviation of the 2.01 engine signal. Here it is necessary to have two different management systems: one with fast response and very tight calibration that keeps engine operation close to the 80 per cent catalyst efficiency window [3], and a second system that results in periodic catalyst operation, which is generally considered beneficial for overall catalyst performance [9].

A qualitative approach is also useful when assessing the performance of different systems. Useful information for the engine management can be extracted by analysing the test datasets. As an example, two gasoline engines of 2.0 and 1.01 displacement are compared in Figs 7 and 8 respectively, by means of exhaust gas flowrate and lambda recordings, versus vehicle speed. The 2.01 engine operates in the slightly rich regime, presumably for the sake of reducing engine-out $\mathrm{NO}_{x}$ emissions, while the 1.01 engine operates at slightly lean fuel mixture. In the case of the 1.01 engine, lambda is calculated from the exhaust gas concentrations, because of UEGO sensor failure. The fuel management strategy in both cases enriches the mixture during accelerations and cuts fuel during decelerations. However, there is a main difference in the engine management strategy applied during deceleration.

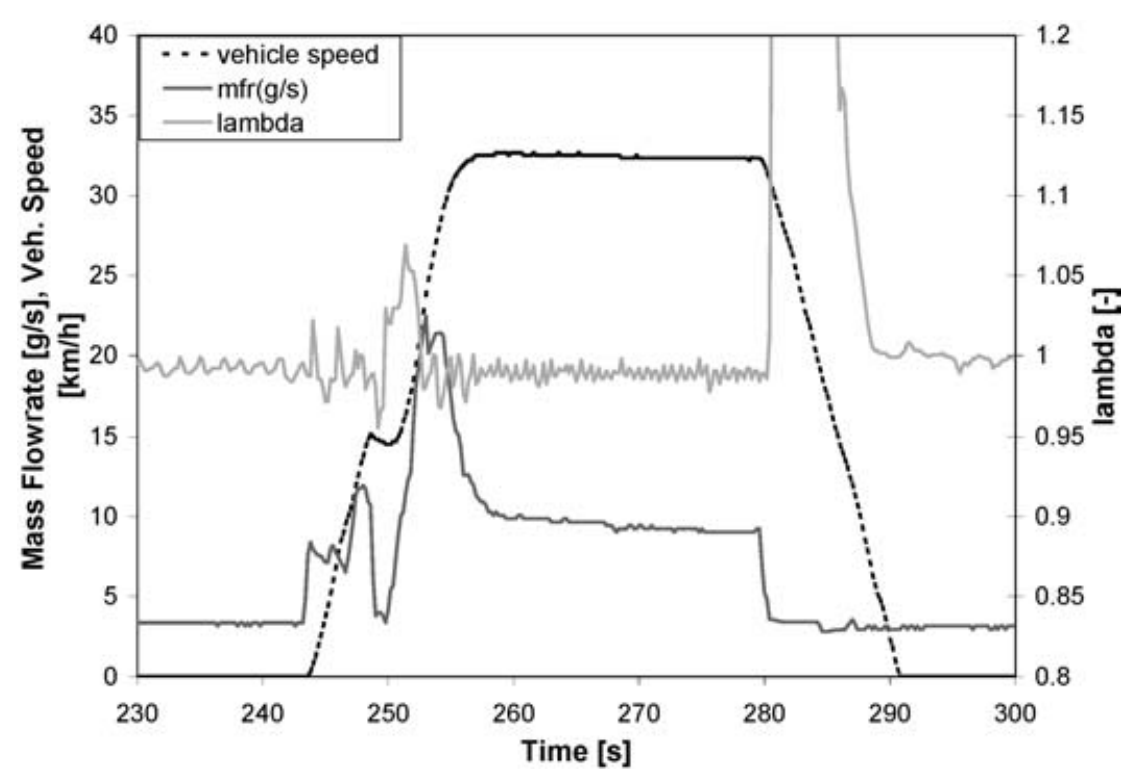

Fig. 7 Low-speed acceleration and deceleration events of the UDC for the case of a 2.01 engine. The engine is operating in a slightly rich regime $(\lambda \sim 0.99)$. The fast data acquisition system $(5 \mathrm{~Hz})$ enables the observation of instantaneous phenomena taking place during gear shifting and deceleration 


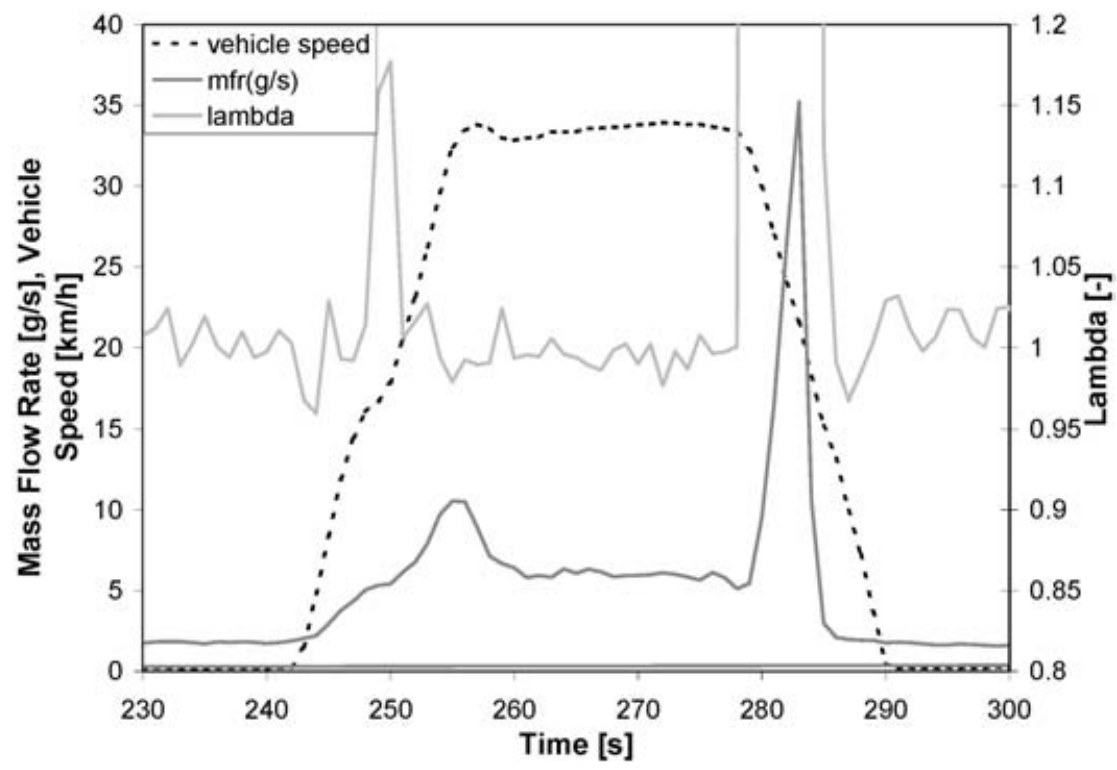

Fig. 8 Low-speed acceleration and deceleration of the UDC for the case of a 1.01 engine. The engine is operating in a slightly lean regime $(\lambda \sim 1.01)$. A slow acquisition rate $(1 \mathrm{~Hz})$ produces aliased signals that constrain the information extraction from an experiment, as shown in the mass flowrate pattern. These cases are analysed better with cumulative graphs

In the case of the 2.01 engine, the throttle is allowed to close according to the driver's command, and fuel cut is applied by the control system. In the case of the 1.01 engine, the control system dips the throttle to the fully open position before closing it. For this reason, a sharp peak of exhaust gas mass flowrate is observed during each deceleration of the 1.01 engine. (Of course, in all strategies in use, a minimum airflow is maintained during fuel cut, i.e. by keeping the idle air bypass part way open, etc., to keep the engine from stalling). Once the specific engine management strategy is identified for a given engine, a visual control over all the respective modes of the driving cycle could reveal possible discrepancies, which suggest measurement errors.

Additional, qualitative observations on the signals can be made. For example, Fig. 8 discussed above presents the results of a $1 \mathrm{~Hz}$ acquisition, with an obviously aliased lambda and mass flowrate signal, in comparison with Fig. 7, which is a $5 \mathrm{~Hz}$ acquisition. This type of qualitative check could be readily computerized by means of power spectral density graphs produced by fast Fourier transformation (FFT).

Further visual checks are possible regarding the response of the mass flowrate signal. In certain cases this signal is taken from the ECU input and is adequately fast, as in Fig. 7, compared with the more sluggish signal of Fig. 8.

\section{DATA SYNCRONIZATION AND PREPROCESSING}

The raw experimental data are time series of gas species concentrations, temperatures, lambda signal, mass flowrate and vehicle speed. LTTE, like other laboratories of this kind, has developed its own standard format, shown in Table 3, for writing down data that also enables automated further processing through routine spreadsheet operations.

Using routine methodologies [10], the raw analyser signals data (dry molar fractions in the case of $\mathrm{CO}, \mathrm{CO}_{2}$, $\mathrm{NO}_{x}$ and $\mathrm{O}_{2}$ ) are transformed into wet molar fractions. At this stage, a cross-checking of oxygen concentration computed on the basis of the lambda signal and the rest of the analyser signals, with the respective one measured directly from the oxygen analyser, supplies useful information on the overall quality of exhaust gas concentration measurements. An example is shown in Fig. 9, where the oxygen concentration measured at the catalyst inlet by a paramagnetic analyser is compared with the computed concentration (based on the lambda signal and the rest of the analysers).

Important pieces of information can be extracted even from the qualitative study of the catalyst inlet and outlet exhaust gas species concentrations at cold start, when the catalyst is inactive. Figure 10 is an example of this

Table 3 LTTE standard format

\begin{tabular}{|c|c|c|c|c|c|c|c|c|c|c|c|c|c|c|c|}
\hline $\begin{array}{l}\text { Time } \\
\text { (s) }\end{array}$ & $\begin{array}{l}\mathrm{CO} \\
\text { meas. } \\
\text { inlet }\end{array}$ & $\begin{array}{l}\mathrm{HC} 1 \\
\text { meas. } \\
\text { inlet }\end{array}$ & $\begin{array}{l}\mathrm{NO}_{x} \\
\text { meas. } \\
\text { inlet }\end{array}$ & $\begin{array}{l}\mathrm{CO} \\
\text { meas. } \\
\text { exit }\end{array}$ & $\begin{array}{l}\mathrm{HC1} \\
\text { meas. } \\
\text { exit }\end{array}$ & $\begin{array}{l}\mathrm{NO}_{x} \\
\text { meas. } \\
\text { exit }\end{array}$ & $\begin{array}{l}\mathrm{CO}_{2} \\
\text { meas. } \\
\text { inlet }\end{array}$ & $\begin{array}{l}\mathrm{CO}_{2} \\
\text { meas. } \\
\text { exit }\end{array}$ & $\begin{array}{l}\mathrm{O}_{2} \\
\text { meas. } \\
\text { inlet }\end{array}$ & $\begin{array}{l}\mathrm{O}_{2} \\
\text { meas. } \\
\text { exit }\end{array}$ & $\begin{array}{l}T \\
\text { inlet } \\
\text { cat. }\end{array}$ & $\begin{array}{l}T \\
\text { exit } \\
\text { cat. }\end{array}$ & Lambda & MFR & $\begin{array}{l}\text { Veh. } \\
\text { speed }\end{array}$ \\
\hline
\end{tabular}




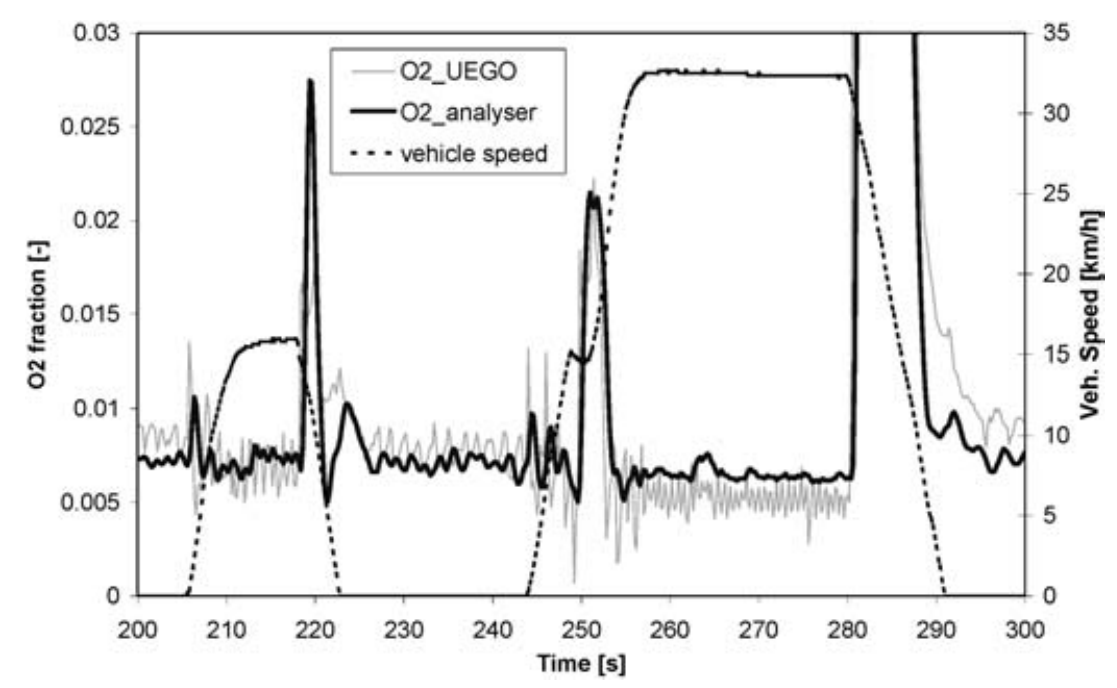

Fig. 9 Comparison of the oxygen fraction in the exhaust gas, computed from the UEGO signal and from the $\mathrm{O}_{2}$ analyser signal in $5 \mathrm{~Hz}$ acquisition. The lambda signal is much faster than the analyser signal. Differences in the mean values may originate from the lambda sensing system calibration or analyser errors

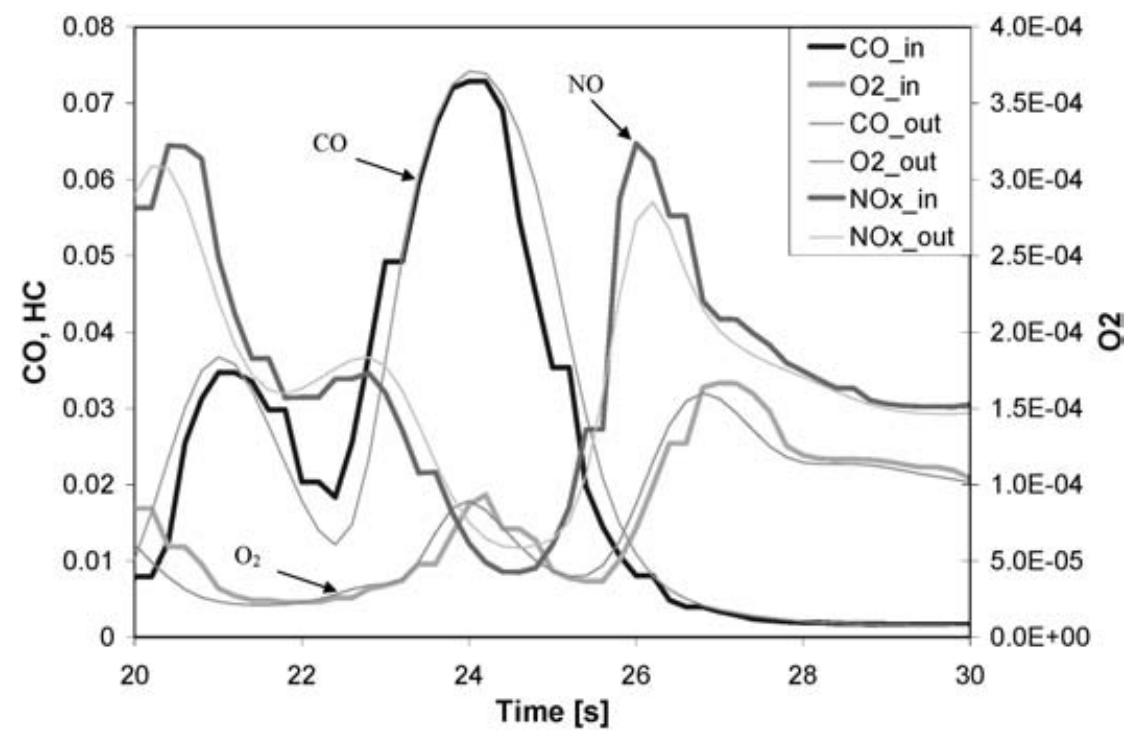

Fig. 10 Acquisition errors in inlet $\mathrm{CO}, \mathrm{O}_{2}$ and $\mathrm{NO}_{x}$ measurements during cold start are apparent in this recording by means of the sudden dislocation of the signal curves at specific time points. This type of error does not appear in the outlet measurements

kind. In the specific example, the acquisition of inlet concentrations suffers from sampling problems (every now and then, the last recorded event is erroneously repeated for a number of sampling intervals). This seems to be a problem of the data acquisition card that destroys the correct phasing of the data, as shown in Fig. 11.

\subsection{Phasing of raw data}

Carbon monoxide emissions from internal combustion engines are primarily affected by stoichiometry [11]. $\mathrm{NO}_{x}$ and $\mathrm{HC}$ emissions, on the other hand, depend on a number of factors. In general, $\mathrm{HC}$ emissions are minimized at $\lambda \sim 1.1$ and are increased at rich mixtures (lack of oxygen) and extremely lean ones (partial burning, ultimate misfires, unburned fuel). $\mathrm{NO}_{x}$ emissions are strongly affected by the combustion temperature and excess of oxygen, thus they are maximized at about $\lambda \sim 1.1$ and are lower in more rich or lean regimes [10].

According to the above reasoning, a valid time correlation of the signals of interest in the present methodology can be attained by means of the following major steps:

1. Vehicle speed in combination with UEGO sensor signal and engine-out temperature is used as the baseline. The response of routinely employed thermocouples with less than $0.5 \mathrm{~mm}$ external sheath diameter is 


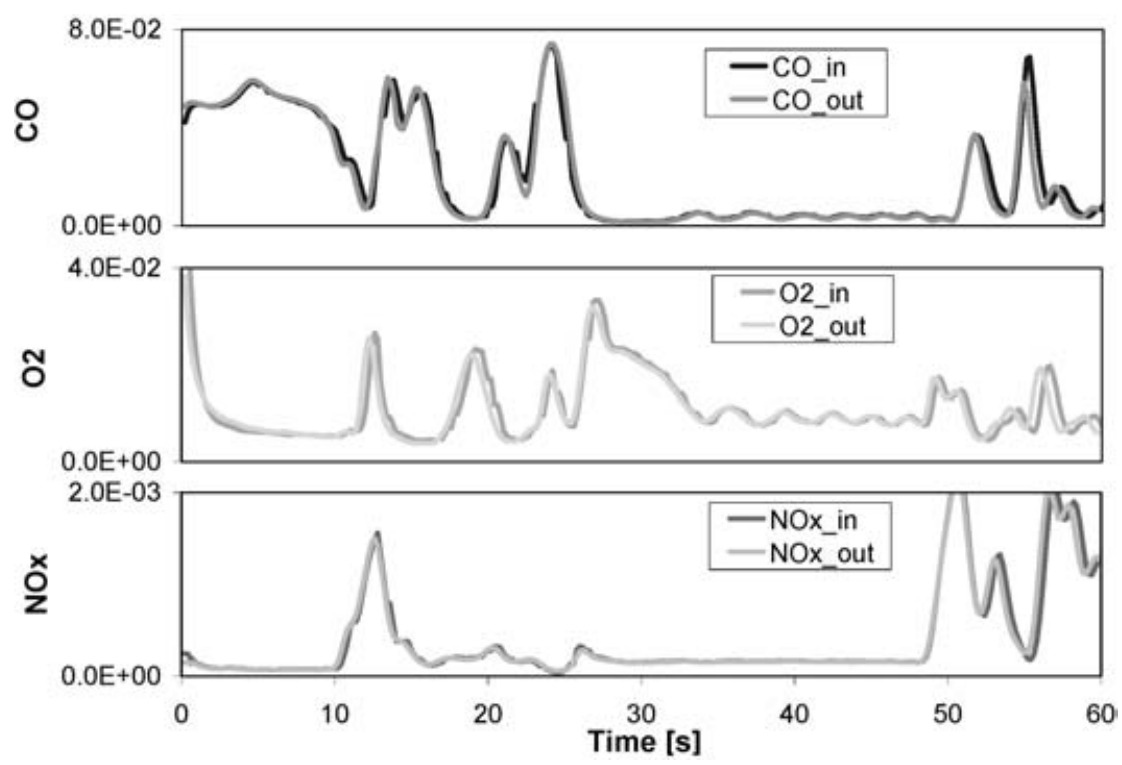

Fig. 11 Several acquisition problems lead to incorrect phasing of the inlet and outlet data time series. In this figure, although all recordings are correctly phased at $t=40 \mathrm{~s}$, they lose synchronization by $t=20$ and $t=55 \mathrm{~s}$. Moreover, the phasing is different for each species recording and varies with time

quite fast (time constant less than $200 \mathrm{~ms}$ ) and the exhaust temperature near the exhaust valve responds quickly to changes in engine operation.

2. Mass flowrate, which is correlated with the lambda signal $(\mathrm{A}+\mathrm{F})$, is phased.

3. The CO signal is correlated and phased with the lambda signal.

4. The $\mathrm{NO}_{x}$ signal is correlated and phased with the lambda signal and exhaust temperature.

5. The HC signal is correlated with the mass flowrate and lambda signals. During accelerations, HC decreases and mass flowrate increases, and during decelerations the $\mathrm{HC}$ emissions may increase owing to the scavenging of remains from the fuel cut.

The correlation of the signals is time independent for the inlet and exit of the converter, as all the measurements are acquired at the same point in each case. Once a part of the signal is synchronized, the complete time series is normally synchronized. Of course, owing to changes in exhaust gas velocity, the input and the output signal cannot be synchronized everywhere. Synchronization of traces of these signals at the beginning of the driving cycle eliminates phase differences coming from different acquisition pipe lengths.

These steps are dependent on the specific engine management system applied in each case. In the case shown, during decelerations, fuel cut is observed, followed by excessively diluted exhaust gas. That is, when lambda increases to large values, $\mathrm{NO}_{x}$ and $\mathrm{CO}$ emissions diminish. This is an example of a minor phase checking step that stems from qualitative observations. In general, correlation factors present a good measure of synchronization, but they must be adapted to each different engine - exhaust system variant through qualitative observations.

Figures 12 and 13 present raw and correlated CO, $\mathrm{HC}, \mathrm{NO}_{x}$ and lambda signals produced by recordings of NEDC test behaviour of the 2.01 engine. Tables 4 and 5 present the respective correlation factors. In Fig. 12, an unrealistic increase in both $\mathrm{O}_{2}$ and $\mathrm{CO}$ during deceleration is observed with the raw (unsynchronized) data. On the other hand, the synchronized (corrected) signals presented in Fig. 13 are consistent, as $\mathrm{CO}$ is seen to increase for rich lambda and to decrease for lean lambda. Tables 4 and 5 present the correlation factors of raw and synchronized data only during acceleration (48-68 s of NEDC) and deceleration modes (80-100 s of NEDC). This is adopted because transient phenomena with high variation in the signals are more convenient for the extraction of correlation factors. Only the correlation factor values that are depicted in bold in these tables could be usefully employed in the manual phasing procedure. However, a computer aided procedure employing standard optimization techniques could fully exploit the information of this table.

Another calculation that is of assistance in checking inlet and outlet concentrations phasing, as well as inconsistencies between analysers, is the subtraction of inlet and outlet measurements while the catalyst is inactive (e.g the first 10-15 s), as follows for the case of $\mathrm{CO}$

$$
\text { Relative error }=\frac{\left|\sum_{t=0}^{10} \mathrm{CO}_{\text {inlet }}-\sum_{t=0}^{10} \mathrm{CO}_{\text {outlet }}\right|}{\sum_{t=0}^{10} \mathrm{CO}_{\text {inlet }}}
$$

Proc. Instn Mech. Engrs Vol. 218 Part D: J. Automobile Engineering 
Table 4 Correlation factors of phased data (deceleration in italics)

\begin{tabular}{lccccccr}
\hline Phased & Lambda & $\mathrm{CO}$ & $\mathrm{THC}$ & $\mathrm{NO}_{x}$ & MFR & $\begin{array}{l}\text { Vehicle } \\
\text { speed }\end{array}$ & $T$ \\
\hline Lambda & 1 & $-\mathbf{0 . 3 1 4}$ & $\mathbf{0 . 4 9 7}$ & -0.64 & $-\mathbf{0 . 3 0 3}$ & 0.25 & 0.25 \\
$\mathrm{CO}$ & $\mathbf{0 . 7 5}$ & 1 & -0.324 & 0.272 & -0.032 & 0.258 & 0.302 \\
$\mathrm{THC}$ & $\mathbf{0 . 1 3 4}$ & 0.184 & 1 & -0.919 & $-\mathbf{0 . 7 5}$ & -0.461 & -0.385 \\
$\mathrm{NO}_{x}$ & -0.052 & -0.127 & 0.433 & 1 & 0.81 & 0.396 & $\mathbf{0 . 3 6 1}$ \\
MFR & $\mathbf{0 . 3 2 5}$ & -0.36 & $-\mathbf{0 . 5 3 6}$ & -0.059 & 1 & 0.692 & 0.638 \\
Vehicle speed & 0.016 & -0.132 & -0.714 & -0.119 & 0.836 & 1 & $\mathbf{0 . 9 8 3}$ \\
$T$ & -0.027 & -0.182 & -0.928 & $-\mathbf{0 . 3 7 1}$ & 0.678 & $\mathbf{0 . 8 9 1}$ & 1 \\
\hline
\end{tabular}

Table 5 Correlation factors of raw data (deceleration in italics)

\begin{tabular}{lccccccc}
\hline Raw & Lambda & $\mathrm{CO}$ & $\mathrm{THC}$ & $\mathrm{NO}_{x}$ & MFR & Vehicle \\
\hline Lambda & 1 & $\mathbf{0 . 6 1 5}$ & $-\mathbf{0 . 4 3 5}$ & -0.061 & $-\mathbf{0 . 3 0 3}$ & 0.26 & \multicolumn{1}{c}{0.25} \\
CO & $-\mathbf{0 . 0 3 8}$ & 1 & -0.178 & -0.042 & -0.157 & 0.087 & 0.089 \\
THC & $\mathbf{0 . 0 7 1}$ & 0.026 & 1 & -0.605 & $-\mathbf{0 . 5 2 9}$ & -0.866 & -0.801 \\
NO $_{x}$ & -0.263 & -0.258 & 0.353 & 1 & 0.67 & 0.608 & $\mathbf{0 . 5 3 6}$ \\
MFR & $\mathbf{0 . 3 2 5}$ & 0.271 & $-\mathbf{0 . 1 0 4}$ & -0.01 & 1 & 0.679 & 0.638 \\
Vehicle speed & 0 & 0.212 & -0.364 & 0.154 & 0.827 & 1 & $\mathbf{0 . 9 8 5}$ \\
$T$ & -0.027 & 0.023 & -0.642 & $-\mathbf{0 . 0 5 6}$ & 0.678 & $\mathbf{0 . 8 9 6}$ & 1 \\
\hline
\end{tabular}

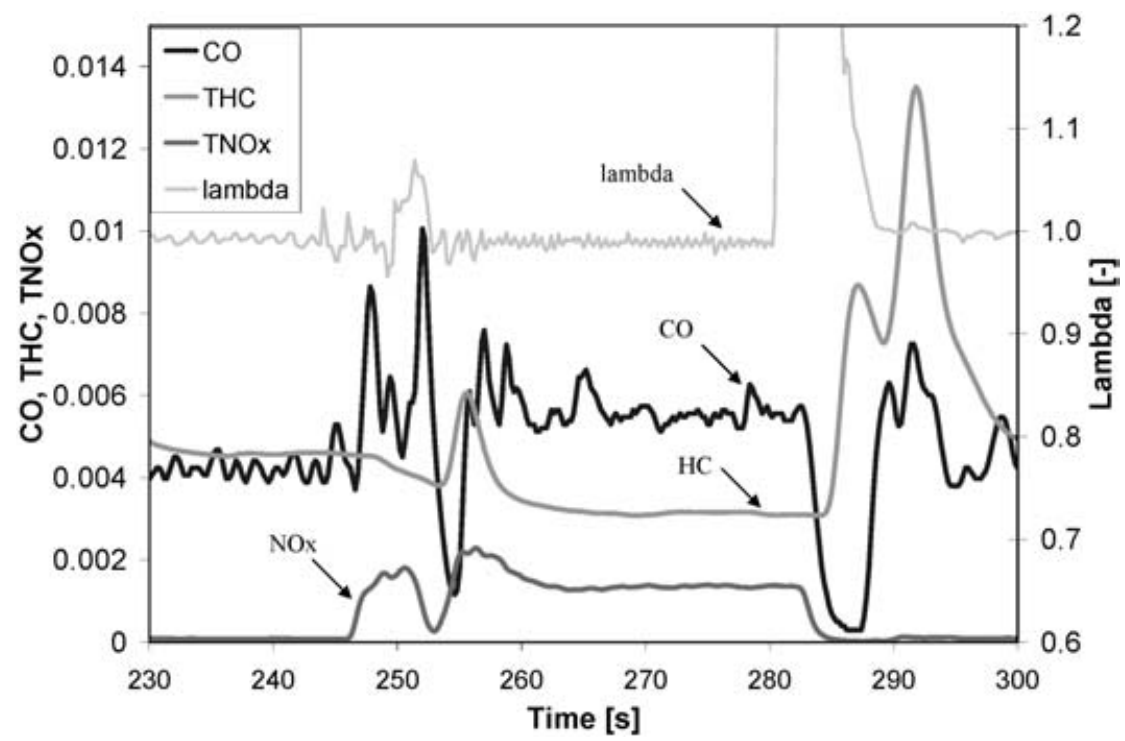

Fig. 12 Additional raw emission concentration data for the test case of Fig. 7. Raw data are incorrectly phased, as becomes apparent by comparing the peak values of the emissions

Ideally, this quantity must be zero. Differences from zero value indicate either wrong phasing of inlet and outlet data or random errors, as different inlet and outlet analyser response or acquisition sampling problems.

\section{MOLECULAR BALANCES OF EXHAUST GAS SPECIES}

All the procedures mentioned above involve engine-out experimental data that are entering the converter. It is of major importance to ensure that these data are error free, in order to assist modelling and design optimization of exhaust treatment devices. This section focuses on the exploitation of information that can be acquired by the application of species and element molecular balances across the catalytic converter. As explained in the previous sections, the composition of the exhaust gas entering the converter is adequately described for the present purpose by seven chemical species: $\mathrm{N}_{2}, \mathrm{CO}_{2}, \mathrm{H}_{2} \mathrm{O}, \mathrm{O}_{2}$, $\mathrm{CO}, \mathrm{HC}$ and $\mathrm{NO}_{x}[\mathbf{1 2}]$.

The transient catalyst performance regarding the consumption of reactants and the production of inert products over the legislated cycle can be visualized by means 


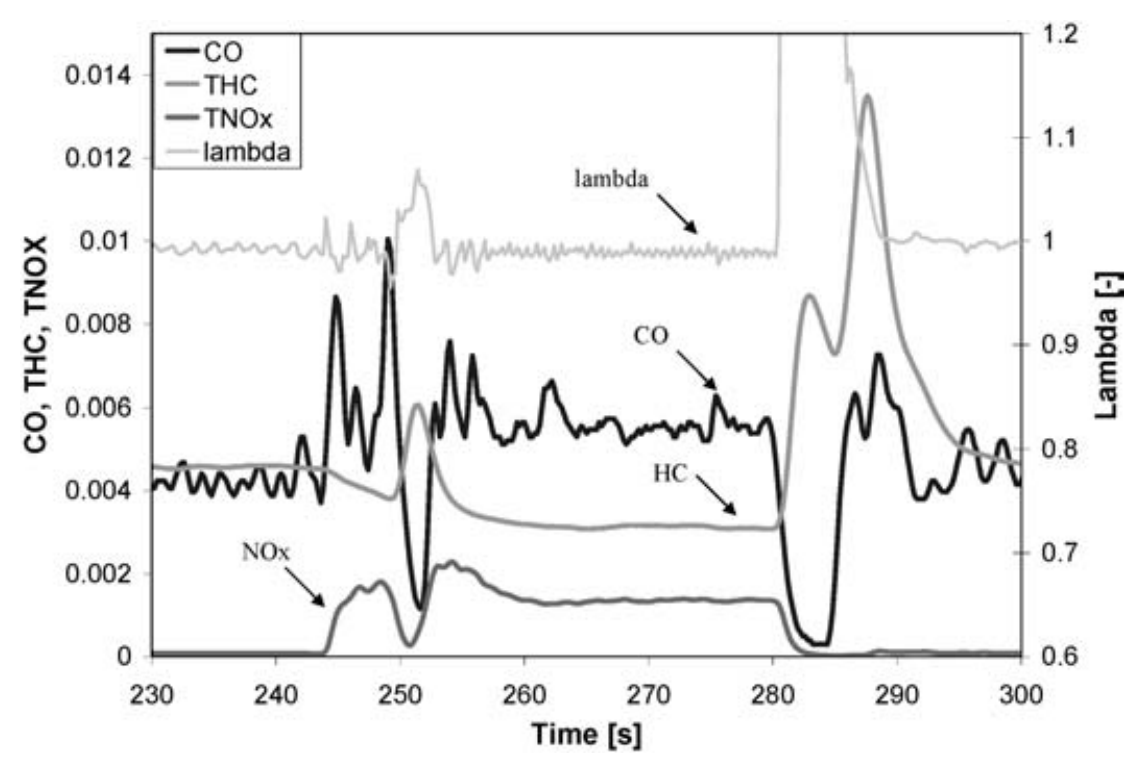

Fig. 13 Correctly phased data of the inlet measurements of the previous figure. Lambda peak values are correctly associated with $\mathrm{CO}$ lows, $\mathrm{HC}$ temporarily increase owing to combustion chamber scavenging and $\mathrm{NO}_{x}$ decrease is mainly correlated with the mass flowrate decrease shown in Fig. 7

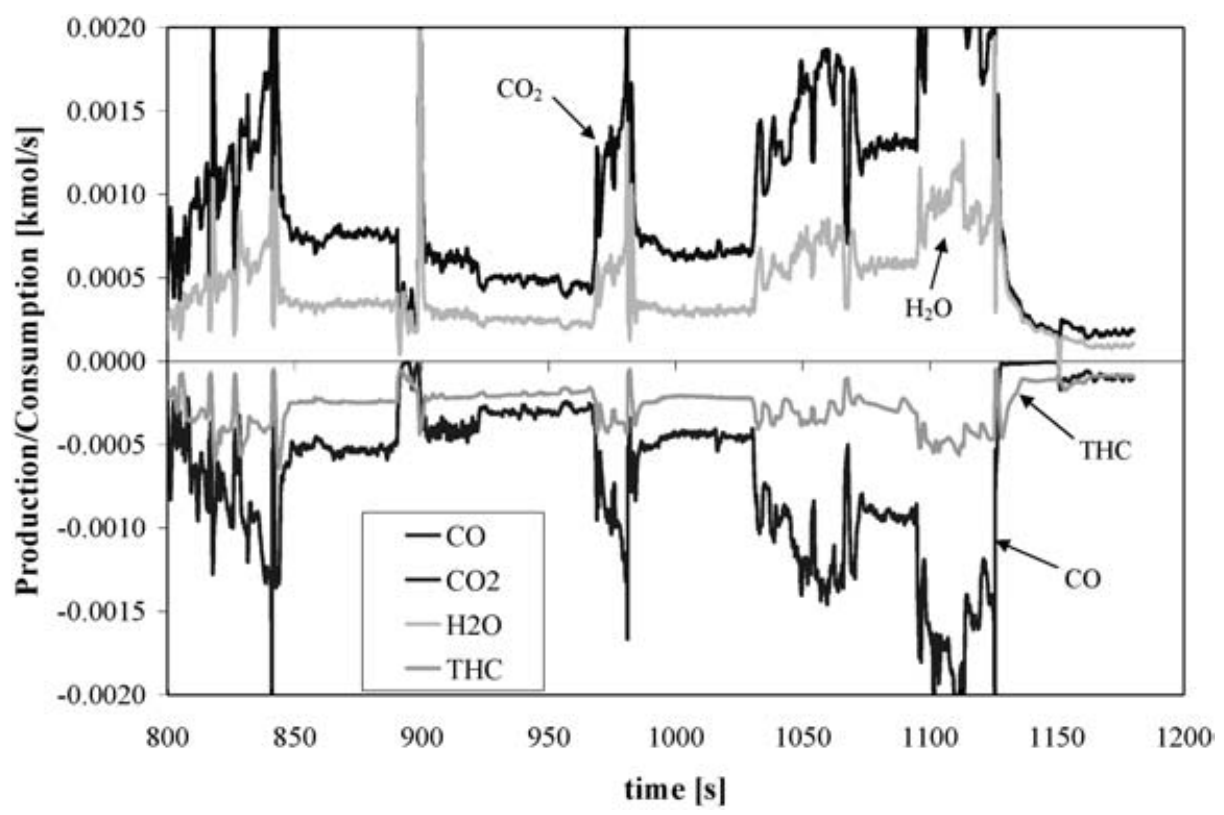

Fig. 14 Species balances of $\mathrm{CO}, \mathrm{HC}$ consumption and $\mathrm{CO}_{2}, \mathrm{H}_{2} \mathrm{O}$ production in a catalytic converter installed on the exhaust line of a 2.01 engine during EUDC. These types of graph reveal additional information on the quality of experimental data and they are used for cross-checking between experiments of the same vehicle. In this case, fluctuations during acceleration at about $1050 \mathrm{~s}$ seem to come from problematic data in the specific regime

of chemical species production-consumption graphs of the type in Figs 14 and 15 (part of the extra-urban driving cycle for two experiments on the same vehicle). A comparison between the two figures reveals differences in the transient emission characteristics. For example, the initial consecutive accelerations of the EUDC produce more intense emission fluctuations in the cycle of
Fig. 15. On the other hand, acceleration of $70-100 \mathrm{~km} / \mathrm{h}$ (the region at about $1050 \mathrm{~s}$ with no gear shift) produces more intense emission fluctuations in the cycle of Fig. 14. This type of observation may be employed to produce further consistency checks between the signals of reactants and products. A check of this kind can be based on elemental molecular balances. As an example, carbon 


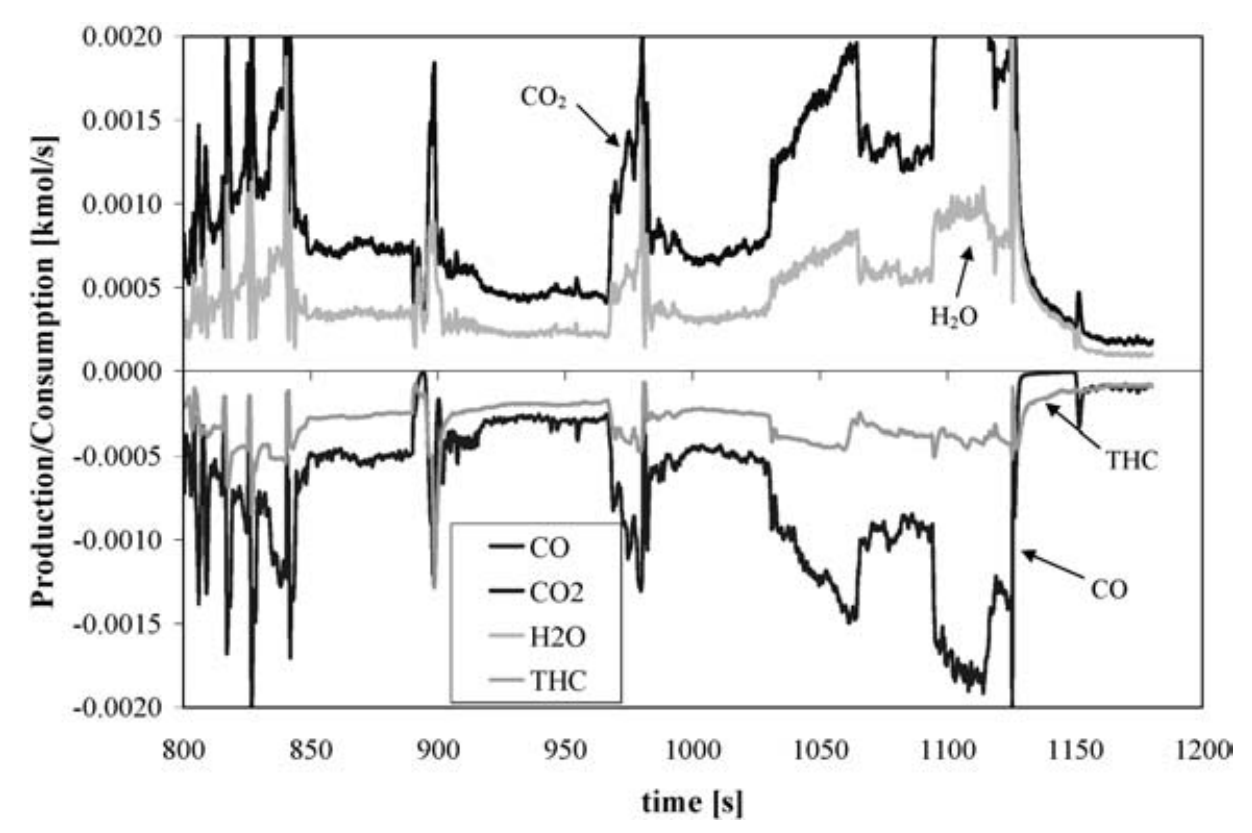

Fig. 15 Species balances of $\mathrm{CO}, \mathrm{HC}$ consumption and $\mathrm{CO}_{2}, \mathrm{H}_{2} \mathrm{O}$ production in a test of the engine of Fig. 14 during the EUDC, with a different catalytic converter. In this case, there are fluctuations during acceleration at about $800 \mathrm{~s}$, while the regime at $1050 \mathrm{~s}$ presents a smooth behaviour

and oxygen balances are presented in Fig. 16 for two NEDC tests of the same engine with different catalysts installed.

Ideally, the elemental carbon balance should be a zero line. This type of behaviour is approximately (within a certain tolerance) demonstrated during the cruise and idle modes of the driving cycle of Fig. 16. On the other hand, there exist observable deviations from the zero line during acceleration and deceleration periods. Generally, the deviations in the carbon balance hint at experimental errors. In the case of transients, a fast response of the order of $0.1 \mathrm{~s}(0-90$ per cent of full scale) would be required for all analysers employed in the acquisition. This could support a valid, say, $5 \mathrm{~Hz}$ acquisition,

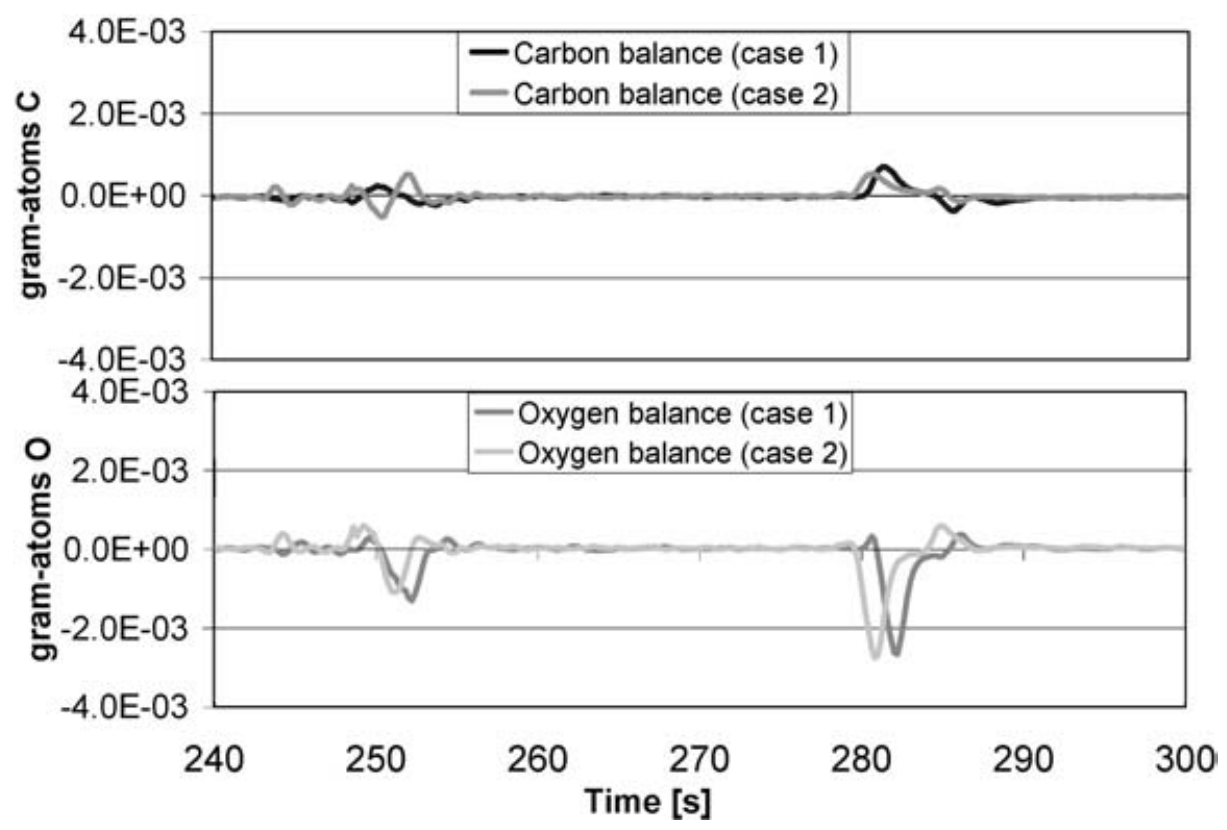

Fig. 16 Elemental balances for $\mathrm{C}$ and $\mathrm{O}_{2}$ across a catalytic converter installed on a 2.01 engine on the NEDC. Ideally, the elemental carbon balance should be a zero line, while the oxygen balance may deviate from zero owing to storage processes. Fluctuations in the carbon balance at about 250 and $280 \mathrm{~s}$ (transient periods) are attributed to the response of the analysers. Negative oxygen values are attributed to storage filling during lean operation of the engine 
provided that accurate phasing is also obtained. Obviously this is not the case in Fig. 16 where the observable deviation could probably be attributed to the usual, more sluggish, analyser response that cannot successfully match the $5 \mathrm{~Hz}$ acquisition.

The situation is more complex as regards the origin of the more pronounced deviations in the oxygen balances. Starting with the observable oxygen deficit during deceleration at about $280 \mathrm{~s}$, this can be mainly attributed to the filling of the oxygen storage. The less pronounced fluctuating deviation during the acceleration at about $250 \mathrm{~s}$ is more difficult to explain, because of the combined effect of a small acceleration enrichment with the associated instability of the control, also affected by the requirements of the gear shift.

Obviously, a certain level of experimental error is justified, and the usefulness of these diagrams lies in the comparison between different tests of the same vehicle and similar exhaust treatment systems. Returning to the example of Fig. 16, and up to a certain level of experimental error tolerance, the two cases are of equivalent quality. In both cases, similar oxygen deficit levels are observed, indicating similar oxygen storage filling behaviour.

\section{QUALITY ASSURANCE PROCEDURE}

The above building blocks may be integrated in a preliminary test data quality assurance procedure that includes computer aided along with manual steps, according to the tentative flow chart of Fig. 17, which is briefly explained below.

Raw data acquired must be first transformed into a standard format adopted by the specific laboratory. A standard format enables further processing of the data in spreadsheets or with software in a simple and errorfree manner. At this point, the acquired dataset is checked for completeness. Previous experience has shown that this type of test usually lacks completeness of data. In some cases, data deficiency can be overcome by calculations. For example, exhaust mass flowrate can be calculated from the $\mathrm{A} / \mathrm{F}$ signal and fuel or air flowrate. In several cases, $\mathrm{O}_{2}$ and $\mathrm{CO}_{2}$ are not measured, but they can be calculated from the rest of the measurements and the lambda signal. Another case is the lack of lambda signal measurements that can be calculated on the basis of the analyser measurements. If so, the missing data are reported in an error log, and a recorded procedure for calculating the missing values is followed, if possible. A good example is the computation of mass flowrate by the CVS volume and dilution ratio, in the case of the legislated chassis dyno procedure with measurements in diluted exhaust. If the dataset is complete, the procedure described in section 3.1 for signal synchronization follows.

The next step is to perform qualitative observations on the operation of the engine in the various modes, the signal quality and other aspects. The summary is recorded and compared with the respective figures existing in the database. Implications of the type of engine, its displacement, management system and the exhaust treatment system installed are employed in the

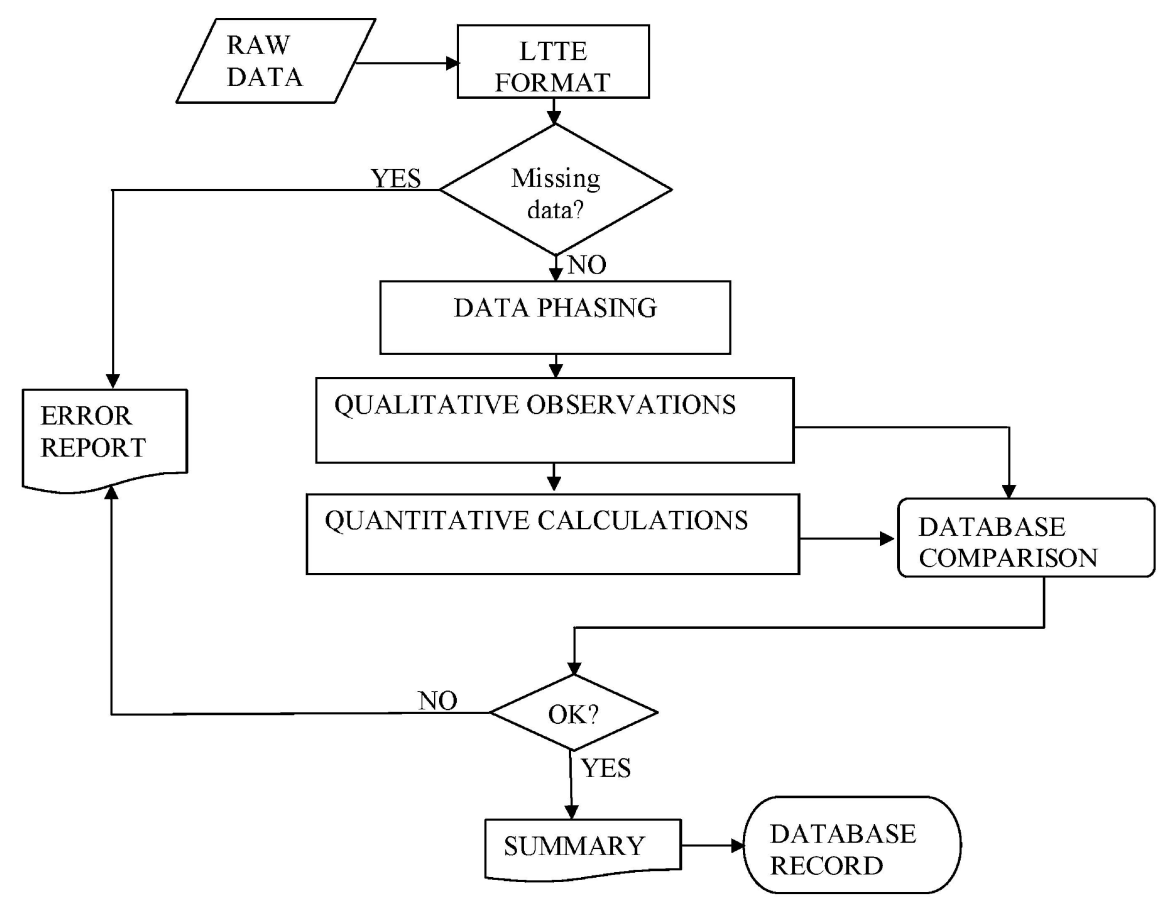

Fig. 17 Flow chart of a preliminary quality assurance methodology. It includes data phasing and cross-checking through qualitative observations and quantitative calculations 
cross-checking of the data. Afterwards, quantitative observations are performed with the assistance of several calculations and graphs produced by the software. Such graphs include molecular balances and cumulative unit emissions of exhaust gas species, as well as a number of cross-checking calculations.

When a case study is successfully completed, it is recorded in the database, with a complete report, for future use.

\section{CONCLUDING REMARKS}

1. Time varying exhaust emissions test data are routinely employed today in exhaust system design and optimization studies.

2. Owing to the multitude of measurement techniques employed in the recording of time series of the exhaust gas species, mass flowrates and temperatures, it becomes vitally important to monitor the quality of data acquisition.

3. In this paper, a preliminary methodology for the quality assurance of time-varying emissions test data is formulated and presented.

4. The first step of the methodology involves modal analysis of the driving cycles. This makes it possible to compare different types of engine and test procedure regarding engine management philosophy and exhaust treatment characteristics.

5. The second step involves a data synchronization and preprocessing procedure.

6. The third step involves checking by means of molecular and elemental balances.

7. Even at this preliminary stage, the methodology gives useful results and is successfully applied in exhaust emissions test data processing and exhaust treatment systems design and optimization.

\section{ACKNOWLEDGEMENT}

The financial support of author G. Konstantas by the Greek State Scholarships Foundation is gratefully acknowledged.

\section{REFERENCES}

1 Koltsakis, G. C. and Stamatelos, A. M. Catalytic automotive exhaust aftertreatment. Prog. in Energy and Combust. Sci., 1997, 23.

2 Kašpar, J., Fornasiero, P. and Hickey, N. Automotive catalytic converters: current status and some perspectives. Catalysis Today, 2003, 77, 419-449.

3 Heck, R. M. and Farrauto, R. J. Automobile exhaust catalysts. Appl. Catalysis A: General, 2001, 221, 443-457.

4 Kandylas, I. P., Stamatelos, A. M. and Dimitriadis, S. G. Statistical uncertainty in automotive emissions testing. Proc. Instn Mech. Engrs, Part D: J. Automobile Engineering, 1999, 213(D5), 491-502.

5 Klingenberg, H. and Schurmann, D. Proposal of new exhaust emission compliance and testing procedures based on averaging. SAE paper 821192, 1982.

6 Leventon, W. New test tools zero in on ultra-low emissions. Electronically published at http//:www.autotestreport.com, March 2001.

7 Adomaitis, R. and Heck, R. Vehicle control strategies effect on catalyst performance. SAE paper 881597, 1988.

8 Watson, H. C. Effects of a wide range of drive cycles on the emissions from vehicles of three levels of technology. SAE paper 950221, 1995.

9 Silveston, P. L. Automotive exhaust catalysis: is periodic operation beneficial? Chem. Engng Sci.., May 1996, 51(10), 2419-2426.

10 Heywood, J. B. Internal Combustion Engine Fundamentals, 1988 (McGraw-Hill).

11 Harrington, J. A. and Shishu, R. C. A single-cylinder engine study of the effects of fuel type, fuel stoichiometry, and hydrogen-to-carbon ratio and $\mathrm{CO}, \mathrm{NO}$, and $\mathrm{HC}$ exhaust emissions. SAE paper 730476, 1973.

12 Heck, R. and Farrauto, R. Catalytic Air Pollution ControlCommercial Technology, 1995 (Van Nostrand Reinhold, New York). 
Copyright of Proceedings of the Institution of Mechanical Engineers -- Part D -Journal of Automobile Engineering is the property of Professional Engineering Publishing and its content may not be copied or emailed to multiple sites or posted to a listserv without the copyright holder's express written permission. However, users may print, download, or email articles for individual use. 